\title{
ANALISIS KINERJA PENYULUH TERHADAP PEMBERDAYAAN KELOMPOK USAHA PETERNAKAN SAPI DI DESA TONDEGESAN KECAMATAN KAWANGKOAN KABUPATEN MINAHASA
}

\author{
Indah Th. P Sondakh, J. A. Malingkas, J. Lainawa*, G. D. Lenzun.
}

Fakultas Peternakan Universitas Sam Ratulangi Manado 95115

\begin{abstract}
ABSTRAK
Tujuan penelitian ini untuk menganalisis kinerja penyuluh terhadap pemberdayaankelompok usaha sapi di Desa Tondegesan Kecamatan Kawangkoan Kabupaten Minahasa. Penelitan ini dilakukan dengan menggunakan analisis deskriptif yang dilakukan pada saat pengumpulan data berlangusng dilapangan. Populasi penelitian adalah seluruh anggota kelompok usaha serentape. Metode pengambilan sampel untuk peternak berdasarkan indikasi untuk menilai kinerja yaitu produktifitas, responsivitas, dan responsibilitas.Hasil penelitian menunjukan bahwa kinerja penyuluh sebagian besar berada dalam kategori berhasil. Keberhasilan kinerja penyuluh dalam tingkat produktifitas dalam kategori berhasil dengan presentase $93,33 \%$, dalam tingkat responsivitas dalam kategori berhasil dengan presentase $73,33 \%$, dan tingkat responsibilitas dalam kategori berhasil dengan presentase 93,33\%. Berdasarkan penelitian di simpukan bahwa kinerja penyuluh terhadap pemberdayaan kelompok usaha di desa Tondegesan Kecamatan Kawangkoan yang di ukur dalam segi produktifitas, responsivitas, dan responsibilitasberhasil.
\end{abstract}

Kata kunci: Kinerja, Penyuluh, Pemberdayaan

Korespondensi (correspoding author) Email :joly@gmail.com
ABSTRACT

\begin{tabular}{|c|c|c|}
\hline \multirow{2}{*}{\multicolumn{3}{|c|}{$\begin{array}{l}\text { ANALYSIS OF } \text { INSTRUCTOR } \\
\text { PERFORMANCE TO EMPOWERING }\end{array}$}} \\
\hline & & \\
\hline CATTLE & BREEDING & BUSII \\
\hline GROUP & AT & $\mathbf{T}$ \\
\hline VILLAGE & OF & $\mathbf{A}$ \\
\hline
\end{tabular}

DISTRICT. The purpose of this study was to analyze the performance of instructors on empowerment of cattle business groups in Tondegesan Village, Kawangkoan District, Minahasa Regency. This research was carried out by using data miles and huberman analysis which was carried out when the data collection took place in the field. The study population was all members of the serentape business group. The sampling method for farmers is based on indications to assess performance, namely productivity, responsiveness, and responsibility. The results showed that the performance of extension agents was mostly in the successful category. The success of the instructor's performance in the productivity level is in the successful category with a percentage of $93.33 \%$, in the level of responsiveness in the successful category with a percentage of $73.33 \%$, and the level of responsibility in the successful category with a percentage of $93.33 \%$. Based on the research,concluded that the performance of the instructor towards the empowerment of business groups in the village of Tondegesan, Kawangkoan Subdistrict which was measured in terms of productivity, responsiveness and responsibilitysuccessful.

Keywords: Performance, Extension, Empowerment 


\section{PENDAHULUAN}

Kegiatan pemberdayaan peternak dimaksud adalah upaya mengubah kesadaran, memperkuat keinginan dan perlakuan masyarakat peternak sebagai obyek atau pelaku yang berperan dalam peningkatan produk peternakan Harry (2001).

Upaya-upaya pemberdayaan masyarakat seharusnya mampu berperan meningkatkan kualitas sumberdaya manusia $(\mathrm{SDM})$ terutama dalam membentuk dan merubah perilaku masyarakat untuk mencapai taraf hidup yang lebih berkualitas. Pembentukan dan perubahan perilaku tersebut, baik dalam dimensi sektoral yakni dalam seluruh aspek/sektor-sektor kehidupan manusia, dimensi kemasyarakatan yang meliputi jangkauan kesejahteraan dari materiil hingga non materiil, dimensi waktu dan kualitas yakni jangka pendek hingga jangka panjang dan peningkatan kemampuan dan kualitas untuk pelayanannya, serta dimensi sasaran yakni dapat menjangkau dari seluruh strata masyarakat.

Lembaga penyuluhan pertanian mempunyai peran strategis untuk pemberdayaan pertanian-peternak karena mempunyai tugas dan fungsi untuk menyelenggarakan pendidikan non formal bagi petani.
Pemberdayaan petani peternak dapat dilakukan melalui pemberian pemahaman baik melalui penyuluhan maupun komunikasi antar-peternak agar mereka mampu memperbaiki sistem pengelolaan usaha peternakan sehingga dapat mencapai tujuan yang diinginkan. Salah satu contoh bentuk pemberdayaan petani peternak ialah mengikutsertaka petani dalam pengambilan keputusan mengenai program pemerintah yang akan dijalankan menyangkut masalah peningkatan produktivitas peternakan seperti, mengajarkan peternak proses insiminasi buatan (IB), pengolahan sumber daya lokal (sisa hasil pertanian) sebagai bahan pakan berkualitas, pelatihan pemanfaatan sisa hasil peternakan menjadi pupuk dan sebagainya. Hardiyanto (2007).

Kegiatan pemberdayaan masyarakat harus mampu mengembangkan teknik-teknik pendidikan tertentu yang imajinatif untuk menggugah kesadaran masyarakat. Dalam rangka peningkatan keberdayaan masyarakat perdesaan (Abdurrahman, 2010).

Penyuluhan pertanian dilakukan agar petani memiliki kemampuan baru untuk menyelesaikan permasalahannya, artinya penyuluh berusaha melakukan perubahan terhadap sasaran yaitu petani.Untuk meningkatkan efektivitas sistem kerja latihan dan kunjungan dari kegiatan penyuluhan guna menumbuhkan 
peran petani, pembangunan pertanian, maka dilakukanlah pembinaan terhadap kelompok-kelompok tani yang telah terbentuk agar nantinya kelompok tani mampu berkembang menjadi kekuatan ekonomi yang memadai dan selanjutnya mampu menopang kesejahteraan anggotanya (Najib Dan Rahwita, 2010).

Penyuluhan adalah kegiatan pendidikan bagi petani yang disesuaikan dengan kondisi petani. Penyuluhan adalah proses mengubah perilaku petani menjadi lebih baik agar mampu memecahkan. tantangan yang dihadapi serta meningkatkan kualitas hidupnya. Sasaran pendidikan dalam penyuluhan pertanian adalah para petani, orang dewasa yang telah memiliki kemampuan tertentu dengan sejumlah pengalamannya, sehingga penyuluhan merupakan pendidikan khusus bagi orang dewasa yang harus sesuai dengan karakteristik orang dewasa tersebut. Penyuluhan harus menerapkan filsafat dan prinsip-prinsip pendidikan khususnya pendidikan untuk orang dewasa, serta memahami karakteristik orang dewasa dengan segala kondisi dan kebutuhannya. Menurut Suhanda, et al. (2008) kinerja seorang penyuluh dapat dilihat dari dua sudut pandang yaitu:

1. Bahwa kinerja merupakan fungsi dari karakteristik individu dan merupakan variabel penting yang dipengaruhi perilaku seseorang termasuk penyuluh; dan

2. Kinerja penyuluh merupakan pengaruh dari situasional dalam terjadinya perbedaan pengelolaan dan penyelenggaraan penyuluhan di setiap kabupaten yang menyangkut beragamnya aspek kelembagaan, ketenagaan, program penyelengaraan, dan pembiayaan (Jahi dan Ani, 2006).

Dalam mewujudkan kinerja, penyuluh di hadapkan pada masalah internal maupun eksternal. Masalah internal dalam hal ini terkait dengan karakteristik penyuluh, sedangkan masalah eksternal diantaranya adalah masalah perbedaan lingkungan kerja yang dapat mempengaruhi perilaku kerja dan motivasi kerja yang tercermin pada kinerja atau job performance mereka.

Sementara konsep pemberdayaan dalam penyuluhan menurut Margono (2001) merupakan ungkapan lain dari tujuan penyuluhan. Masyarakat berdaya berarti masyarakat yang mampu, tahu, mengerti, paham, termotivasi, berkesempatan, melihat peluang, dapat memanfaatkan peluang, berenergi, mampu bekerja sama, tahu berbagai alternatif, mampu mengambil keputusan, berani menghadapi risiko, mampu mencari dan menangkap informasi, serta mampu 
bertindak sesuai situasi. Tujuan pembangunan melalui pemberdayaan masyarakat dapat terwujud bila pembangunan tersebut bukan hanya pembangunan yang bersifat ekonomik semata Andriyani et al. (2017).

Jika dilihat dari proses operasionalisasinya, maka ide pemberdayaan memiliki dua kecenderungan, antara lain : pertama, kecenderungan primer, yaitu kecenderungan proses yang memberikan atau mengalihkan sebagian kekuasaan, kekuatan, atau kemampuan (power) kepada masyarakat atau individu menjadi lebih berdaya. Sumodiningrat, (2002). Menurut Kartika (2015) Masyarakat adalah kelompok sosial yang juga memiliki potensi yang sangan besar bila dapat mengarahkan kemampuan dirinya dalam mengembangkan berbagai kompetensi yang dapat memberikan nilai tambah dalam kehidupannya, dan menurut Kawulur (2017) Modal sosial berupa kepercayaan, norma sosial, jaringan sosial, nilai-nilai sosial, dan timbal balik.

Desa Tondegesan merupakan salah satu desa di Kecamatan Kawangkoan Kabupaten Minahasa. Menurut hasil survey, di desa Tondegesan terdapat petani yang memelihara ternak sapi serta terdapat kelompok tani ternak sapi yang sudah pernah dan beberapa kali mendapat penyuluhan beternak sapi dari BP3K maupun dari Perguruan Tinggi. Upaya penanggulangan kemiskinan yang paling strategis dalam era otonomi daerah dapat di rumuskan dalam satu kalimat yaitu "berikan peluang kepada keluarga miskin dan komunitasnya untuk mengatasi masalah mereka secara mandiri" (Almasri et al., 2014).

\section{METODE PENELITIAN}

\section{Tempat dan Waktu Penelitian}

Penelitian ini dilaksanakan pada bulan september sampai dengan oktober tahun 2018, bertempat di Desa Tondegesan Kecamatan kawangkoan kabupaten Minahasa.

\section{Metode Pengambilan Sampel}

Populasi penelitian adalah seluruh anggota kelompok usaha serentape. Metode pengambilan sampel untuk peternak secara purposive sampling berdasarkan indikasi untuk menilai kinerja yaitu produktifitas, responsivitas, dan responsibilitas. Ketiga indicator ini dipilih dengan alasan bahwa indikator ini dirasa telah cukup mewakili dari beberapa indikator yang banyak digunakan untuk menilai kinerja suatu organisasi publik (Arif, 2009).

\section{Analisis Data}

Analisis data yang digunakan dalam penelitian ini adalah analisis deskriptif, yang mengacu pada analisis data yang di kemukakan oleh Miles and 
Huberman (1984), mengemukakan bahwa aktivitas dalam analisis data kualitatif dilakukan secara interaktif dan berlangsung secara terus menerus sampai tuntas, sehingga datanya sudah jenuh. Pada saat wawancara, peneliti sudah melakukan analisis terhadap jawaban responden yang di wawancarai. Bila jawaban responden yang di wawancara setelah dianalisis terasa belum memuaskan, maka peneliti akan melanjutkan pertanyaan lagi, sampai tahap tertentu, di peroleh data yang di anggap kredibel dan dapat dipercaya.

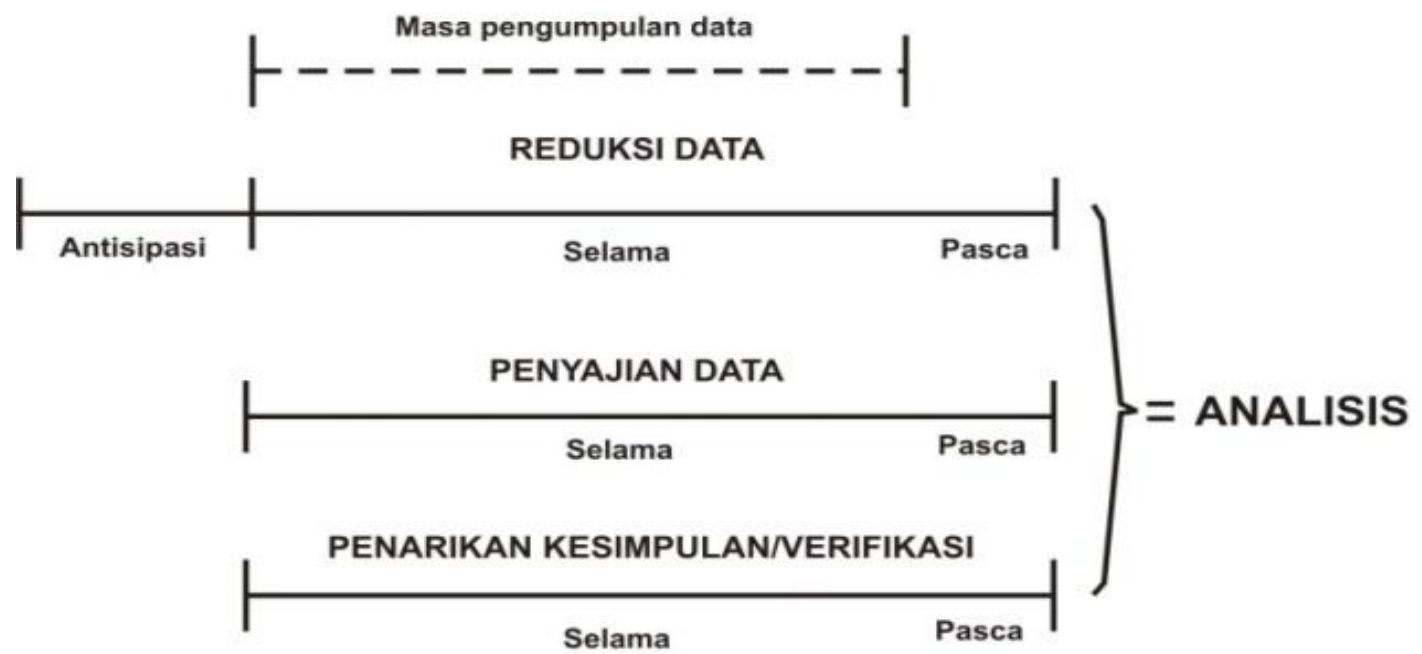

Gambar. 1 Komponen

Dalam Analisis Data 


\section{HASIL DAN PEMBAHASAN}

\section{Karakteristik Responden}

Responden yang di ambil dalam penelitian ini adalah anggota kelompok usaha Serentape yang ada di Desa Tondegesan, Kecamatan Kawangkoan Kabupaten Minahasa. Jumlah responden dalam penelitian ini adalah 15 orang yang terdiri dari umur, tingkat pendidikan, jumlah kepemilikan ternak dan pengalaman beternak. Di amati secara deskriptif, sedangkan untuk kinerja penyuluh terhadap pengembangan kelompok usaha di analisi dengan menggunakan analisis data Miles and Huberman (1984).

\section{Umur}

Umur merupakan salah satu faktor yang dapat mempengaruhi produktifitas kerja seseorang. Tingkat umur seseorang akan berpengaruh terhadap kemampuan dalam mengingat atau menyimpan memori.Dari hasil penelitian menunjukan bahwa kisaran umur peternak cukup bervariasi yaitu antara 30-70. Kebanyakan responden berumur 40-60 tahun yaitu sebanyak 9 orang (60\%) dan paling rendah $<40$ tahun sebanyak 2 orang $(13,34 \%)$. Hal ini berarti rata-rata petani peternak di dalam kelompok usaha berada pada kelompok usia produktif untuk melakukan pekerjaan atau menjalankan usahanya, karena terdapat 9 orang pada usia 40-60 yaitu usia yang masih termasuk dalam kategori pertengahan usia. Sampai tingkat umur tertentu kemampuan fisik manusia semakin tinggi sehingga produktifitas meningkat tetapi semakin bertambahnya umur maka kemampuan akan semakin menurun maka hasil responden menurut umur dapat di lihat pada tabel 1.

Tabel.1 Distribusi Responden Menurut Umur

\begin{tabular}{cccc}
\hline & & Peternak & Sampel \\
\cline { 3 - 4 } No & UmurResponden & Orang & $(\%)$ \\
\hline 1 & $<40$ & 2 & 13,34 \\
2 & $46-60$ & 9 & 60 \\
3 & $>60$ & 4 & 26,66 \\
\hline & Jumlah & 15 & 100
\end{tabular}


Tabel 2 Tingkat Pendidikan.

\begin{tabular}{cccc}
\hline & & Peternak & Sampel \\
\cline { 3 - 4 } No & Tingkat Pendidikan & Orang & $(\%)$ \\
\hline 1 & Tingkat Lulusan SD & 4 & 26,66 \\
2 & Tingkat Lulusan SMP & 3 & 20 \\
3 & Tingkat Lulusan SMA & 7 & 46,67 \\
4 & Tingkat LulusanSarjana & 1 & 6,67 \\
\hline & Jumlah & 15 & 100 \\
\hline
\end{tabular}

\section{Tingkat Pendidikan}

Pendidikan berpengaruh pada cara berpikir peternak yang akan melaksanakan kegiatan usaha ternaknya. Tingkat pendidikan yang termasuk jalur pendidikan sekolah terdiri dari pendidikan dasar, pendidikan menengah, dan pendidikan tinggi. Peternak yang pendidikan formalnya lebih besar kemungkinan akan lebih mudah menerima inovas serta perubahan dalam hal beternak sapi khususnya di lokasi penelitian. Menurut Lestari et al (2009), bahwa petani yang berpendidikan tinggi relatif lebih cepat melaksanakan adopsi inovasi.

Hasil penelitian menunjukan bahwa data pendidikan peternak di Desa Tondegesan adalah SD (26,66\%), SMP (20\%), SMA (46,67\%), Sarjana $(6,67 \%)$. Tingkat pendidikan di Desa Tondegesan masih tergolong mampu mengambil keputusan dan menerima inovasi baru dalam berusaha.

Tabel 3. Klarifikasi Responden Berdasarkan Jumlah Kepemilikan Ternak di Kecamatan Kawangkoan, Kabupaten Minahasa.

\begin{tabular}{cccc}
\hline & & Peternak & Sampel \\
\cline { 3 - 4 } No & JumlahKepemilikanTernak & Orang & $(\%)$ \\
\hline 1 & - & 7 & 46,67 \\
2 & $1-5$ ekor & 6 & 40 \\
3 & $>10$ & 2 & 13,33 \\
\hline & Jumlah & 15 & 100 \\
\hline
\end{tabular}




\section{Jumlah Kepemilikan Ternak}

Pada umumnya usaha ternak sapi di kecamatan kawangkoan merupakan peternak tradisional.

Hal ini di buktikan dari hasil wawancara anggota kelompok usaha pada tahun 2018 pada umumnya sebagian besar anggota memiliki populasi ternak berkisar 1-5 ekor.

\section{Kinerja Penyuluh Dalam}

Pengembangan Kelompok Usaha

Dalam penelitian ini, anggota kelompok usaha Serentape yang di jadikan responden sebanyak 15 orang yang terdapat dalam 1 Desa. Penelitian kinerja penyuluh dapat ukur melalui 3 indikator sebagai berikut:

\section{Produktivitas}

Produktivitas kerja adalah

kemampuan dalam berproduksi di bandingkan dengan input yang di gunakan, seorang peternak dapat di katakan produktiv apabila mampu menghasilkan hasil ternak yang sesuai dengan harapan.

Dalam hal ini produktivitas penyuluh sangat di butuhkan dalam rangka pemberdayaan kelompok usaha. Kinerja penyuluh dalam melakukan pekerjaannya sesuai dengan perencanaan yang telah ditetapkan juga termasuk dalam produktivitas.

Tabel 4 menunjukan bahwa sebanyak 14 peternak $(93,33 \%)$ dalam kategori Produktif, 1 peternak $(6,67 \%)$ dalam kategori Tidak Produktif.. Pencapaian tingkat produktivitas anggota kelompok usaha menunjukan bahwa kinerja penyuluh berada dalam kategori sudah berhasil karena sebanyak 14 responden mengatakan bahwa tingkat produktivitas penyuluh sudah memuaskan baik dalam segi pemberian materi dan rutinitas dalam menjalankan penyuluhan.

\section{Tabel 4. Tingkat Kepuasan Responden Terhadap Produktivitas Penyuluh}

\begin{tabular}{cccc}
\hline Indikator & Kategori & Jumlah Respon & Presentase \% \\
\hline & Produktif & 14 & 93,33
\end{tabular}

Produktivitas Penyuluh

Tidak Produktif

$1 \quad 6,67$


Tabel 5. Responsivitas peternak terhadap penyuluh

\begin{tabular}{cccc}
\hline Indikator & Kategori & Jumlah Respon & Presentase \% \\
\hline & Baik & 11 & 73,33
\end{tabular}

Responsivitas

Tidak Baik 26,67

15

100

\section{Responsivitas}

Responsivitas merupakan salah satu kriteriadalam mengukur kinerja penyuluh . Dalam hal ini responsivitas yang di ukur yaitu berupa kemampuan Tabel 5 menunjukan bahwa sebanyak 11 peternak $(73,33 \%)$ dalam kategori baik, 4 peternak $(26,67 \%)$ dalam kategori tidak baik. Pencapaian tingkat responsivitas anggota kelompok usaha terhadap penyuluh menunjukan bahwa kinerja penyuluh berada dalam kategori sudah berhasil.

\section{Responsibilitas}

Responsibilitas menjelaskan tentang tanggung jawab seseorang dalam menyelenggarakan penyuluhan serta pelayanan yang sesuai dengan kebutuhan peternak sapi. penyuluh harus memiliki responsivitas mengenai kebutuhan dan masalah yg timbul dlm kelompok usaha

terhadap tugas-tugasnya yang berhubungan dengan peran seseorang kepada pihak yg dilayani dalam hal ini adalah peran penyuluh terhadap kelompok usaha peternak, masalah rendahnya responsibilitas penyuluh menjadi fokus perhatian. Hal ini dapat dilihat dari beberapa aspek faktual yang muncul misalnya kurangnya pengetahuan atau penguasaan materi saat penyuluhan berlangsung.

Tabel 6. Reponsibilitas kinerja penyuluh dalam memberikan materi pada saat penyuluhan

\begin{tabular}{cccc}
\hline \multicolumn{1}{c}{ Indikator } & \multicolumn{1}{c}{ Kategori } & Jumlah Respon & Presentase \% \\
\hline \multirow{2}{*}{ Responsibilitas } & Menguasai & 14 & 93,33 \\
& Tidak Menguasai & 1 & 6,67 \\
\hline & & 15 & 100 \\
\hline
\end{tabular}


Hasil olahan data pada tabel 6 . Menunjukan bahwa kinerja penyuluh dalam memberikan materi pada saat penyuluhan dalam kategori menguasai $(93,33 \%)$, dan tidak menguasai $(6,67 \%)$. Pencapaian tingkat responsibilitas kinerja penyuluh sudah berhasil, hal ini menunjukan bahwa penyuluh sudah betanggung jawab melalui penguasaan materi yang di berikan setiap penyuluhan berlangsung.

\section{KESIMPULAN}

Berdasarkan penelitian dapat di simpukan bahwa kinerja penyuluh terhadap pemberdayaan kelompok usaha di desa Tondegesan Kecamatan Kawangkoan yang di ukur dalam segi produktifitas, responsivitas, dan responsibilitas sudah berhasil.

\section{DAFTAR PUSTAKA}

Abdurrahman, 2010. Hasil Evaluasi Program Pembangunan Peternakan Dan Tinjauan Masa Depan Melalui Perspective Analysis. Dinas pertanian dan kehutanan. http://disnaksulsel.com. Diakses pada tanggal 23 oktober 2011.

Almasri, Devi, dan Deswimar. 2014. Peran program pemberdayaan masyarakat desa dalam pembangunan pedesaan. 5(1):41-46

Andriyani A. A, Martono E, dan Muhamad 2017 Pemberdayaan masyarakat melalui pengembangan desa wisata
Ketahanan Sosial Budaya Wilayah 23.(1):1-16

Arif D. B. 2009. Kinerja Kantor Pertanahan Dalam Pelayanan Sertifikasi Tanah (studi deskiptif Atas Pelayanan Sertifikasi Peralihan Hak Atas Tanah di KantorPertanahan Kota Surakarta 2008-2009). Surakarta: Universitas Sebelas Maret.

Hardiyanto. 2007. Komunikasi pembangunan dan pemberdayaan. Jurnal Trans disiplin Sosiologi Komunikasi Dan Ekologi Manusia. Institut Pertanian Bogor. Bogor. 1.(3):1978-4333

Jahi A, dan Ani L. 2006. Kinerja penyuluh pertanian di beberapa kabupaten di provinsi Jawa Barat. Jurnal Penyuluhan. 2.(2):34 - 42

Kartika P. 2015. Optimalisasi peran mayarakat dalam pemberdayaan masyarakat melalui pendidikan luar sekolah. Jurnal Empowerment. 3.(1):2252-4738

Kawulur S. K. 2017. Modal sosial kelompok tani "Citawaya" di Desa Talikuran 1 Kecamatan Sonder Kabupaten Minahasa. Jurnal Sosial. 13.(3):31-44

Lestari. W, H. Sjafril dan I. Nahri 2009. Tingkat adopsi inovasi peternak dalam beternak ayam broiler di Kecamatan Bajubang Kabupaten Batang Hari. JIIP.12.(1):1-9

Margono S. 2000. Memantapkan Posisi dan Meningkatkan Peran Penyuluhan Pembangunan dalam Pembangunan. Dalam Proseding Seminar IPB Bogor: Pemberdayaan Sumber Daya Manusia Menuju Terwujudnya Masyarakat Madan. Pustaka Wira Usaha Muda. 
Miles dan Huberman. 1984. Qualitative Data Analysis a Sourcebook of New Methode. London: Sage Publications.

Najib dan Rahwita. 2010. "Peran penyuluhan petani dalam pengembangan kelompok tani di
Desa Bukit Raya Kecamatan Tenggarong”. Jurnal Ziraa'ah. 28.(2):116-127

Suhanda, N. S., A. Jahi, B. G. Sugehen dan D.Susanto. 2008. Kinerja penyuluh pertanian di Jawa Barat. Jurnal Penyuluhan. 4.(2):101-108. 